\title{
Reciprocal Activism in Digital Spaces
}

In the middle of the novel coronavirus pandemic, Dr. Mina $\mathrm{H}$ (a pseudonym), a young doctor living in the Nahr al-Bared refugee camp, sent out a plea on Facebook and WhatsApp to her extended family and village network around the globe for food and medicine. Just as the rest of the world was experiencing shortages of basic goods like flour, toilet paper, and protective gear, Palestinian refugees were facing dire shortages of food and other essential items. Within a few days of her plea, thousands of dollars had poured into the camp to help buy basic goods like food and medicine.

Refugees around the entire world are confronting suffering unlike anything most of us have seen in our lifetime: 68.5 million refugees have lost their homes, their livelihoods, and access to basic goods and services. Yet Dr. Mina's pleas did not go unheeded. The response illustrates the strategy Palestinians have developed for helping the community weather scarcity and catastrophe.

In her memoir Circle of Quiet, Madeleine L'Engle asserts that communities maintain their wholeness and thrive when the gap between our virtuous selves and our daily actions is a narrow one. Building on this idea, Bryan Stevenson asserts in Just Mercy that when there is scarcity, violence, and injustice, "There is no wholeness outside of our reciprocal humanity." (2014, 290). Reciprocity helps us reduce that gap. It gets people to give greatly of themselves even in terrible conditions. Readers of this book can learn a lot from Palestinian refugees about how to survive catastrophe and solve collective problems while remaining united. We can extend Palestinian refugee strategies to our own suffering communities, closing the gap between our virtuous selves and our daily actions by engaging in reciprocal activism.

\section{LESSONS LEARNED FROM PALESTINIAN REFUGEES}

This book has looked in depth at how Palestinian refugees use digital spaces to inspire transnational reciprocal exchanges. Here I consider how communities, 
refugee and otherwise, might replicate these patterns of reciprocity to weather the inevitable storms of uncertainty and scarcity.

The catastrophic conditions that Palestinians face today are not unique. We live in deeply troubled times. There are ever-increasing numbers of refugees, migrants, "informals," and "stateless" people fleeing violent conflict, climate disasters, and catastrophes like the novel coronavirus pandemic in all corners of the globe (De Soto 1989). At the 2019 World Economic Forum in Davos, the climate justice activist Greta Thunberg pleaded with the global community to push for climate change measures, telling the audience, "I want you to act as you would in a crisis. I want you to act as if our house is on fire. Because it is" (Thunberg 2019). Indeed, in recent years millions of people have literally fled their burning houses because of conflict and climate change.

While we wait as political elites and established institutions dither, this book seeks to answer the simple question, How do communities solve collective problems in suboptimal conditions? In other words, when our houses are burning and no state or organization is stepping up to offer protection and services, how does a community help itself? My research shows that reciprocal exchanges are an adaptive and resilient community response to the needs of the impoverished, the marginalized, and the stateless. We can extend the reach of such exchanges into communities with dysfunctional states and unresponsive institutions.

Experimental research on engendering reciprocity-defined as a cooperative interaction marked by the exchange of favors and privileges-suggests that communities can overcome selfish impulses even in times of great scarcity. Key conditions for reciprocity include the enforcement of norms, or shared understandings of expected behavior, via repeated interactions in familiar group settings (Axelrod 1984; Boyd et al. 2003; Fehr and Gächter 2002; West, Griffin, and Gardener 2006). However, this scholarship has not previously been extended to real-world refugee communities and digital spaces of interaction. Examining the digital behavior of Palestinians living in camps in Lebanon and the diaspora has provided new data on the role of reciprocity and ICTs in refugee community building. The representation of precrisis kinship networks in digital spaces has created high-context interactions where norms of honor and loyalty are easily enforced using shame as a form of social control. In effect, Palestinians are using "old" ways of connection and obligation and making them new again in digital spaces.

Palestinians have endured generations of intractable conflict and shifting and ambiguous political economic rule. Kinship networks have been central to the survival of the Palestinian community under these conditions. The community used ahl and hamula networks to resolve dilemmas during the Ottoman and British mandate periods of rule. These networks offered a framework of relationships and trust with easily enforceable norms, enabling the community to raise funds and cooperate to solve collective problems. Even after the social upheaval caused 
by the Nakba in 1948, the community strategically used malleable notions of honor, shame, and loyalty to obtain needed goods and services.

Inside the refugee camps, Palestinian families and villages clustered in familiar groupings. Even as community members were forcibly pushed or voluntarily migrated from the camps in search of economic opportunity, the same kinship networks structured individuals' identity and obligations. Before the internet, communities used analog tools, such as village history books, to develop a "geography of the displaced" through which the camp community could craft and rebuild their family and village connections. Village elders and the authors of these books served as communal gatekeepers who established clear understandings of the behavior and obligations associated with kinship networks. The village history books forged transnational and intergenerational connections, but over time, as the crisis continued, their limitations became evident: the cost of producing them, a tendency toward static understandings of the community, and dwindling readership and participation.

ICTs have provided a dynamic new platform for Palestinians to reimagine their transnational network and the nature of reciprocity in a digital era. Most Palestinian families and villages have their own Facebook pages, WhatsApp groups, and private online chat rooms. By projecting their precrisis kinship networks into digital spaces, refugee communities have formed high-context places where users know one another's lineage, family legacy, and, most important, norms of appropriate behavior.

Palestinians living in the diaspora are encouraged to send economic remittances back to their family and village still stuck in the refugee camps. One motivator is the use of $a y b$, or shame. The managers of Facebook group pages have become digital gatekeepers who enforce community obligations by shaming those who fail to send remittances. In many ways, digital gatekeepers replicate the role of the real-world village elders who have traditionally enforced community behavioral norms. Shame is an exceptionally powerful tool, and while it may motivate altruistic behavior, it can also be used to harm marginalized groups like women and queer communities. Though elite institutions and dominant social narratives uphold rigid patriarchal interpretations of appropriate Palestinian behavior, some family units are pushing against these stiff understandings and embracing more expansive notions of Palestinian identity and social norms.

ICTs serve as a platform for more than just the exchange of economic remittances. The sociological scholarship on migrant, diaspora, and refugee communities reveals that diaspora community members engage in the exchange of social remittances as well-ideas, behaviors, and values that flow between and among transnational communities and "home" (Levitt 1998, 2001). In these digital space, younger generations of Palestinians in the camps and the diaspora can interact without interference from traditional real-world gatekeepers. They share new 
ideas of how they might interact with the world around them and toward each other. Transnational political experiences in democratic spaces provide hope for a reimagined Palestinian political future. But the empowerment of new digital gatekeepers can also challenge the enforcement of communal norms and undermine the established network of reciprocal exchanges.

Certainly, digital spaces will not serve as a magic bullet capable of solving all the community's ills. Life is far from perfect in Nahr al-Bared. Given the ubiquitous lawlessness and endemic scarcity in the camp, we might expect its community to devolve into "nasty, brutish" behavior. Yet the refugee community is able to solve collective problems, such as accessing water, food, medicine, and other goods and services, with no regular police force or official judicial structure. Trust and reciprocity are abundant among refugees and their transnational network. Despite the political, economic, and legal forces that threaten to atomize the community, refugees strategically use digital spaces to inspire reciprocal exchanges and solve problems.

As our houses continue to burn, we can extend the lessons learned from Palestinian kinship networks in digital spaces to more general forms of reciprocal activism in digital spaces .

\section{BLUEPRINT FOR RECIPROCAL ACTIVISM}

Certainly it will not be easy to shift global conditions that deny refugees basic rights and dignities. During my last interview of 2019, a young Palestinian American woman worried, "You see all this awesome person-to-person exchange of help and services in our [Palestinian] village community, but I wonder, can this be scaled up? Can we get people from outside the village to care too?" An acquaintance at a (prepandemic) dinner party commented, "The problem with refugees is just so big, there is nothing someone like me can really do to help. We need a humanitarian organization and world leaders to solve the problems." There are times when the sheer volume of refugees and the catastrophic conditions in which they live may seem overwhelming. Yet this book offers a window into the resilience of marginalized communities in a broken world.

In response to those wondering about the possibility of scaling up individual exchanges, I submit that this book shows the radically transformative power of individual decisions. The trickle of remittances across the globe from a multitude of ordinary people has generated support essential for the refugee community's survival. A young Palestinian boy is now healing from his critical burns and on his way to a "new normal" life; a Palestinian woman graduated as the first woman doctor in her family and is serving sick patients; people who die in Nahr al-Bared can now be buried with dignity. The virtuous circle of people helping other people continues to expand outward in countless small ways. 
The examples in this book show that each of us has the power to transform injustices, especially in places where conflict may be latent. In latent conflict, the suffering and needs of others and potential pathways for remedying them are hidden, usually because there is a low level of awareness of needs and a lack of parity between those suffering and those with control over or access to valuable resources (Curle and Dugan 1982).

We tend to imagine that the peacemakers must be the heads of state, elite political parties, or international agencies. However, at a recent meeting among practitioners and academics at conference titled "Building Sustainable Peace" at the University of Notre Dame's Kroc Institute, presenters reminded us that peace building is not the realm of the elite: it is historically rooted in the actions of everyday people. In particular, Lisa Schirch, director of the Toda Peace Institute, reminded the audience that peace building "is fundamentally a micro-level endeavor" (Schirch 2019). Taking a cue from this insight, my blueprint for justice radically decenters the transformative power for peaceful change away from huge organizational structures and large operating budgets. Certainly, there is a place for UN organizations and large humanitarian institutions, and by offering my strategies I am not condoning the abrogation of state and institutional responsibility for relieving the suffering of refugees and other groups. But all too often we forget that we are connected to one another with or without the conduit of a state or organizational structure. We, that is, you and $I$, can rediscover our common humanity through reciprocal exchanges.

The stories of Palestinian refugees show that each of us has the power to become a reciprocal activist. We have the power to solve problems like access to personal protective equipment (PPE) to those on the front lines during the coronavirus pandemic. Appallingly, there has been a lack of access to PPE not only for frontline medical workers but also among the grocery clerks and gig workers who have been keeping our communities fed during the prolonged waves of the pandemic. Low-paid workers have long suffered from access to basic services and protections. Most of them have established digital networks where they share stories of their suffering and needs. For example, clerks at most Trader Joe's grocery stores have their own Facebook groups and find ways to support one another.

A central insight of theory on mutual-aid societies-organizations that provide benefits or other help to members who are affected by things such as death, sickness, or unemployment, among other crises-is that when individuals in groups, "can support, help, and influence each other in a reciprocal manner, the inherent potential exists to provide group members with a sense of greater personal, interpersonal, and environmental control over their lives to negotiate high risk situations" (Glitterman and Schulman 2005, preface). Mutual-aid societies encourage individuals to engage with others to protect themselves and develop a plan for action to solve problems in challenging circumstances. My blueprint for reciprocal 
activism focuses on how to enter these spaces for mutual aid and transform circumstances using digital technology. The plan begins with each of us gaining the permission of a marginalized community's digital platform moderator and then entering their digital spaces with the explicit intention to listen and learn from them what they need to make a real difference in their daily lives right now.

Adam Curle and Maire Dugan offer a model of how to transform unpeaceful relations into peaceful ones. Unpeaceful relations are those in which either or both parties are damaged, possibly through physical violence but also through economic or psychological harm. Their model of "conflict transformation" applies not only to situations of open conflict, such as war or sectarian violence, but also to latent conflicts.

Many refugee situations fall into the category of latent conflict. Those with privileges and access to resources often see media reports of large numbers of refugees fleeing violent conflict, but less is reported about the long-term warehousing of refugees, the protection gaps they face, and the conditions of their daily lives. Though global attention may focus on the Syrian refugee and undocumented border crossing (UBC) crises today, refugee crises persist in places like Darfur, Sudan, Liberia, Afghanistan, Iraq, Kosovo, and Rwanda, some of them dating back to conflicts in the previous century. (Jacobsen 2005, 1).

Unpeaceful conditions are marked by structural violence, in which an individual's potential is curtailed as a result of socioeconomic forces (Galtung 1969). For example, the inability of refugees to access basic services and protections creates an unpeaceful space. Peaceful spaces, by contrast, are collaborative spaces where individuals, with the help of others, realize their own potential and where there is a high level of awareness and parity between the suffering and those who might help (Curle and Dugan 1982). Awareness refers not only to whether all parties involved know of the suffering but also to the degree to which all parties are aware of its sources and the possibilities for addressing the situation. Parity considers the balance of power between those that are suffering and those who might help.

Lack of awareness is evident in the scant media coverage of what happens to migrants and refugees after their initial exodus. Even refugees who for a time are front-page news find themselves with very little follow-up care from the communities that sensationalized their stories. When the body of Alan Kurdi, a Syrian refugee toddler, washed ashore on a Turkish beach on September 2, 2015, the world wept. He was buried in Kobani, Turkey, next to his mother and brother, who also drowned. The story of how his father, his village, and his neighborhood endured the tragedy is nowhere to be found.

Accordingly, Curle and Dugan suggest that the first step in transforming a latent conflict is to increase awareness, "to begin the processes of informing people about the issues at stake and empowering people to become agents of change" (1982, 21). Given the lack of coverage in popular media outlets, refugee digital networks offer a means of increasing public awareness and closing the parity gap. Awareness can 
increase when activists gain the permission of the gatekeepers to enter these digital spaces with the explicit intention of listening to and learning from those who are actually suffering.

In Pathologies of Power (2003), Paul Farmer sets out three steps by which activists can increase awareness and begin to shift the balance of power: observe, judge, and act. Though he focuses on the issue of human rights in the medical arena, his approach is also applicable to combating other forms of deep structural inequalities. Activists seeking to aid refugees and other marginalized communities can observe the suffering and needs of refugees by reading refugee posts in social media or watching their videos; they can judge what skills or resources they can offer that help meet those needs; and they can act on this new information by sending money through a digital app or offering their services. These actions may be small: sending US \$10, proofreading a résumé for a refugee applying for a job, or offering English-language lessons on a digital video platform. In turn, the recipient of the gift may then repay the gift by helping another in the community to "pay it forward." These everyday actions can help create a wholly interconnected community capable of surviving catastrophe.

In I've Got the Light of Freedom (1995), Charles Payne documents the extreme oppression, violence, and poverty that Black Americans faced in Mississippi in the years preceding the civil rights movement. Structural violence was so normalized that state officials, sheriffs, and local white residents regularly colluded to carry out public ritualized lynchings and mutilations of Black people. The stories of the civil rights activists Ella Baker and Septima Clark are examples of community organizing and activism that increases awareness and parity between those with access to resources and power and those who are suffering (Payne 1995). These extraordinary women partnered with Black communities in the Mississippi Delta to empower local people to teach others what they needed to know and forge pathways to accessing it. Long-term development of capacities within a community and the creation of collaborative alliances among ordinary people are important in transforming unpeaceful conditions. This strategy proved effective in the deep South because it shielded people from the state crackdowns that large-scale demonstrations elicited and empowered people to solve their own problems.

Histories of the civil rights era often focus on the extraordinary leadership of Martin Luther King Jr. and dramatic, large-scale protests. However, community organizing, as practiced by Ella Baker and Septima Clark, demonstrated that ordinary people are capable of extraordinary acts to improve the conditions in which they live, despite facing everyday violence and oppression (Payne 1995). Instead of relying on hierarchical power structures and traditional elite leadership, community organizers focus on people-to people interactions in which people who are suffering share their stories with one another and with outsider activists; then they collaborate in order to meet those needs, with an emphasis on specific local needs, sensitivity to the structure of the local community, and an appreciation of 
its culture. Payne terms this a "developmental style" of community organization that increases the agency and capacity of those affected by the problems, regardless of whether tactical objectives are met.

This strategy for activism shows that ordinary "people have the right and capacity to have some say-so in their own lives" (Payne 1995, 68). Participatory political and educational activities, akin to the digital spaces where refugees create groups and share their stories, help the communities define their own problems. Baker and Clark developed "schools" where community members shared their stories, in writing and aloud. Sharing these stories led them to the collective realization that they had a story to tell that was a contribution to society and that provided lessons on how to solve their own problems. Baker emphasized that "strong people do not need strong leaders, they simply need each other" and that one must "start where the people are" to find solutions to the problem (Payne 1995, 77, 68). Ordinary people today can go to the digital spaces of communities in need and listen to their stories, their problems, and their solutions-and then act.

One might suppose that my blueprint for people-to-people online activism is made with academic naivete, because most of us are not part of the fabric of precrisis kinship networks that make Palestinian digital spaces so effective, and digital spaces are rife with misinformation. However, biological kinship is not essential for access to and participation in kinlike networks (see Stack 1974; Scott 2009; Hajj 2014, 2016). Though core parts of Palestinian refugee identity are based on historical events, anyone can become part of this network, "like family," by participating in networks of reciprocity and engaging in the transnational digital exchanges. Through reciprocal exchange, the social bond is (re-)formed and cemented (Stack 1974).

Moreover, participation in exchanges can be on a small scale, as simple as sending $\$ 10$ to a community in need through Western Union ${ }^{1}$, using a digital platform to amplify the community's voice, or sharing expertise or skills with a member of that community. Certainly, engaging in exchanges of money or other resources with online-only acquaintances poses a degree of risk. However, there is a certain racial and socioeconomic bias in suspecting that a member of a refugee community is lying when asking for money or services, yet willingly handing over credit-card and other personal information when purchasing from an online megastore. ${ }^{2}$ Both transactions involve risk. However, the positive externalities associated with giving $\$ 10$ to a refugee (whether or not they use it to fund their education or a medical procedure) surely outweigh those of buying fast-fashion jeans online.

\section{CONCLUSION}

Palestinian refugees' digital networks provide critical insights into how reciprocity works in difficult conditions. The blueprint for reciprocal activism that I prescribe begins with the understanding that the suffering of others touches us. We are in 
that suffering and a part of it, whether or not we choose to engage with it. If those communities do not thrive, then ultimately none of us can thrive. The appropriate measure of peaceful conditions around the globe is the well-being of those most "broken" among us and our own health, and this is inescapably one measure. We exist in an inescapable, interconnected web of relations and obligations. My hope is that this book inspires others to step into these digital networks to affect realworld change for the good.

To reiterate, the lessons from Palestinians refugees provide simple but powerful steps for reciprocal activism. Here is a list of steps we can take right now to improve the conditions for refugees, and other marginalized communities, following the principles of Curle and Dugan (1982) and Farmer (2003).

1. Hop online and research the digital networks used by refugees and other marginalized communities. A great place to start for Palestinian refugees is the Palestine Remembered website (www.palestineremembered.com), where each village and camp has its own profile page and a link to its Facebook group. There are also digital message boards where one can contact people from the community. Almost every precrisis community has its own web presence. For help finding those communities online, contact the Critical Refugee Studies Collective (https://criticalrefugeestudies.com).

2. Contact the Facebook group or digital platform page manager to ask permission to enter the space in order to learn about individual needs. Even if the page is public, it is still good practice to get the consent of the community.

3. Observe. Spend some time increasing your awareness of the community's problems. Read, watch, listen, and learn from the stories and news that community members post.

4. Judge. Make a moral judgment about the information you have learned. You are not a neutral observer. Your judgment might read something like this: "The suffering of this marginalized community is wrong, and my (in) action is contributing to that suffering." It can feel hard to implicate ourselves in the suffering of others. This begins the process of shifting power imbalances so that we see a direct connection between our own power and those suffering around the world.

5. Act. Make a choice about the best way you can help the community meet their needs in the midst of a protection gap. Perhaps the answer is to give money when need arises, as in a medical emergency. If you do not have much money, perhaps you have a skill (teaching English, editing résumés or helping with school essays, or knitting warm hats and mittens, to name just a few) that you can put to good use. Giving freely to strangers online requires us to "risk trusting" (Stack 1974). Although it may feel unsettling, this is how collaboration begins to pave the way for more peaceful conditions. 
The moment we send money or offer a service to another person, we enmesh ourselves in the social networks of refugees and adopt some of the expectations of loyalty and honor, and the deep feelings of shame associated with denying help to another person.

These individual acts do not absolve elites or institutions of responsibility; they simply mean that you and I are stepping up right now. Institutions and leaders can be held responsible even while we take personal responsibility to help other people: the two are not mutually exclusive.

We can complement and build on the power of existing community refugee networks, listen to their needs and requests, and buoy them with our own resources to close the protection gap. Kinship networks can expand to include others who agree to follow and expand on communal norms of honor, collective reliance, and loyalty and thus become "like family." According to Thomas Henry Huxley (1853), a community has a nucleus of specific ideas of how to behave but no outer boundary: rather, it has an expansive notion of who can be incorporated into that community if they agree to the core sentiment that the community deserves to exist and meet its basic needs. By engaging in these very small reciprocal exchanges, we begin to recognize our collective humanity and to heal the brokenness of the world today. 